\title{
LA DIFUSIÓN DEL LENGUAJE TERAPÉUTICO A TRAVÉS DE LA LITERATURA GERENCIAL Y DE AUTOAYUDA
}

\author{
Maria Medina-Vicent \\ https://orcid.org/0000-0002-2716-6786 \\ Universitat Jaume I \\ http://dx.doi.org/10.15304/ag.39.2.5910
}

\section{Resumen}

La sociedad del "nuevo espíritu del capitalismo" se caracteriza por la profusión del lenguaje terapéutico entre la población, un tipo de lenguaje que responde al desarrollo del malestar que la posmodernidad y el capitalismo feroz causan en los individuos. En dicho contexto, valores como la autonomía, el éxito, la creatividad y el empoderamiento pierden su poder de transformación social para convertirse en herramientas disciplinarias al servicio del sistema neoliberal. En el presente artículo abordaremos dos herramientas que consideramos, contribuyen a la difusión de este tipo de lenguaje: la literatura gerencial dirigida a la clase directiva y la literatura de autoayuda dirigida al público general. Sostendremos que ambos tipos de literatura se caracterizan por un fuerte componente disciplinario y ponen en juego las mismas lógicas discursivas y valores, buscando la mercantilización de las capacidades de los individuos.

Palabras clave: autoayuda, lenguaje terapéutico, régimen disciplinario, neoliberalismo.

\begin{abstract}
The "new spirit of capitalism" society is characterized by the profusion of therapeutic language in the population, a type of language that responds to the individual malaise caused by postmodernism and fierce capitalism. In this context, values such as autonomy, success, creativity and empowerment lose their social transformation power and become disciplinary tools at the service of the neoliberal system. In this article, we address two tools
\end{abstract}

Recibido: 23/03/2019. Aceptado: 11/06/2019. 
that we believe disseminate this type of language: popular management literature, which addresses the managerial class, and self-help literature, which addresses the general public. We argue that both types of literature are characterized by a strong disciplinary component which places at stake the same discursive logics and values to seek the commodification of individuals' capacities.

Keywords: self-help, therapeutic language, disciplinary regime, neoliberalism.

\section{Introducción}

El mundo actual se vertebra sobre los discursos del emprendimiento, la automejora constante, el sacrificio personal y el éxito (Alonso y Fernández Rodríguez, 2018; Bröckling, 2015; McGuigan, 2014). Dichas lógicas discursivas nos remiten a un escenario mayor en el que la mercantilización de las capacidades de los individuos está a la orden del día, ya que la lógica gerencial se ha convertido en el "sentido común" de nuestro tiempo (Alonso y Fernández Rodríguez, 2013c), transformando la esfera social e individual en una dimensión más del orden mercantil. Este marco de sentido nos remite a otro mayor referido al neoliberalismo, un sistema económico en el que la intervención del Estado sirve para "purificar el mercado de la competencia mediante un marco jurídico cuidadosamente adaptado" (Laval y Dardot, 2013, p. 63). Sin duda, la clave de dicho orden económico y social se centra en la lógica normativa que lleva aparejada: "La concepción que hace de la sociedad una empresa formada de empresas es inseparable de una norma subjetiva nueva, que no es exactamente la del sujeto productivo de las sociedades industriales" (Laval y Dardot, 2013, p. 325), tiene, por tanto, una dimensión relativa a la conformación de las subjetividades contemporáneas que nos remite al mismo tiempo a conceptos como el de lógica o paradigma.

En esta difusión del nuevo espíritu del capitalismo (Boltanski y Chiapello, 2002), referido a un sistema de ideas, valores y creencias que legitiman las jerarquías y las relaciones de poder subyacentes al sistema neoliberal, el lenguaje terapéutico es un aspecto central. Es decir, para conseguir la expansión y adhesión de los individuos a dicha lógica, se precisa que todos compartan el mismo lenguaje, los mismos valores y creencias. El lenguaje terapéutico aglutina la lógica de la gestión empresarial y la convierte en la base de comportamiento individual.

Partiendo del reconocimiento de esta realidad, el objetivo central de este artículo de investigación es reflexionar en torno a dos de las herramientas de 
difusión centrales del lenguaje terapéutico - la literatura gerencial y la literatura de autoayuda - para identificar cuáles son los principales discursos y valores que se difunden a través de ambas y qué implicaciones tienen para la configuración de las subjetividades contemporáneas. A grandes rasgos, la literatura gerencial dirigida a la clase directiva supone la expansión de la lógica neoliberal en el ámbito de las organizaciones; mientras que la literatura de autoayuda traslada esta misma lógica gerencial entre el público general, contribuyendo a la incorporación del discurso de la gestión de uno/a mismo/a en el día a día de los individuos. Por tanto, ambos géneros literarios son instrumentos centrales en la pervivencia y difusión del neoliberalismo, e influyen en la conformación de nuestras identidades, convirtiendo la precariedad en una base más de nuestros proyectos vitales (Muñoz-Rodríguez y Santos-Ortega, 2017), y la inversión en capital humano en una constante de nuestras trayectorias (López-Ruiz, 2007).

Mediante el cumplimiento del objetivo central que se acaba de exponer pretendemos demostrar que ambos tipos de literatura ponen en juego las mismas lógicas discursivas y los mismos valores, buscando la consecución de la mercantilización de las capacidades de los individuos. Es decir, mientras que la primera se centraría en la consecución de la eficiencia en los procesos de gestión empresarial y actuaría como fórmula disciplinaria dentro de la propia organización; la segunda se encargaría de cumplir con una misión disciplinaria sobre los cuerpos de los/as trabajadores/as y la ciudadanía en el plano de sus vidas privadas (González Gil, 2018; Rimke, 2010). Así, estaríamos hablando de dos herramientas que funcionarían, desde una perspectiva foucaultiana (Foucault, 2007), como herramientas disciplinarias que contribuyen a la conformación del individuo como empresario de sí mismo. Por esta razón algunos autores reclaman una necesaria reflexión crítica sobre los escritos manageriales (Adler, Forbes y Willmott, 2007; Alvesson y Willmott, 1992; Gantman, 2017).

Así pues, la relevancia de este trabajo reside en la operación de desentrañar las principales lógicas discursivas y argucias semánticas que se ponen en juego en este tipo de literatura para difundir entre la población ciertas premisas de comportamiento que vienen a cumplir con los intereses del sistema neoliberal. La estructura que se seguirá es la siguiente. En primer lugar, se realizará una aproximación a los rasgos principales de la literatura gerencial. En segundo lugar, se tratarán de identificar los puntos de confluencia de dicha literatura con la literatura de autoayuda, para mostrar cómo ambas sirven para la difusión de la lógica neoliberal destinada a influir en las subjetividades contemporáneas y los valores sobre los que 
dichas identidades se construyen (Laval y Dardot, 2013). Por último, se identificará el proceso central al que contribuyen, así como los discursos que confluyen en estas obras para reproducir un individuo neoliberal.

\section{La literatura gerencial}

La literatura popular del management, managerial o gerencial difunde las modas de gestión principalmente entre la clase directiva empresarial, pero también al resto de la sociedad (Collins, 2000; Huczynski, 1993; Jackson, 2002). Al igual que los discursos gerenciales, sus contenidos y prescripciones varían en función de los cambios que se producen en el contexto mercantil. Dicha literatura agrupa un conjunto de ideas presentes en el pensamiento económico y determina/influye/refleja la actuación del/la directivo/a de la organización empresarial moderna. Se trata de obras que suelen encontrarse en las librerías bajo el epígrafe "libros de empresa", y aunque se centren en temáticas relacionadas con un aspecto concreto de los negocios, lo hacen desde una "perspectiva muy generalista, más cercana a unos principios de acción (una filosofía de la tarea, si se quiere denominar así) que a acciones concretas (dado que cada compañía tendrá una problemática particular)" (Alonso y Fernández Rodríguez, 2013a, p. 46).

A su vez, los contenidos de esta literatura permiten de algún modo justificar la posición de superioridad de la élite managerial, configurada como una élite en las sociedades occidentales actuales, tanto en la estructura empresarial como en el imaginario colectivo de la ciudadanía (Abrahamson, 1991). Es decir, las ideas y prescripciones que podemos encontrar en la literatura managerial están directamente relacionadas con la profesión de los/ as managers y el entorno laboral en el que se inscriben. Pero no solamente esto, sino también con la imagen del gerente y directivo de éxito como aquel modelo en el que nos tenemos que reflejar. Dichos profesionales se encargarán de traducir las premisas de gestión de la literatura a la práctica (Gowler y Legge, 1991), por esta razón son tan importantes las prescripciones que se lanzan desde este tipo de obras. Para poder desarrollar estas funciones, antes deberán conseguir la adhesión de las personas subordinadas a la consecución de los objetivos manageriales (Weick, 1995), tarea que se consigue con la difusión de la ideología managerial a través de dicha literatura. Esta difusión ideológica también va unida a la consecución de la adhesión por parte de la ciudadanía, al orden económico neoliberal, y a la lógica del empresario de uno mismo (Foucault, 2007; Scharff, 2015b) como base rectora de la vida de los individuos. 
Así pues, este conjunto de imágenes referidas a la empresa no sólo llegan a los cuadros directivos, sino que definen las concepciones sociales sobre la misma: "el imaginario managerial articula, así, un conjunto complejo de elementos simbólicos que condensan distintas imágenes de la organización y atribuyen sentido a la tarea misma de gestionar" (Alonso y Fernández Rodríguez, 2006, p. 128). Ante la disolución de las grandes teorías económicas, ahora convertidas en ideas, conceptos y premisas vulgarizadas, la gestión empresarial se aborda de forma muy simplista adquiriendo un gran carácter prescriptivo que aporta recetas prácticas para el management. Se podría señalar que con la compra de estas obras se espera el acceso a una serie de claves que van a dar resultados en la actividad profesional, como indica Huczynski (2006, p. 137): "in its promotion, including explanation, the buyer must feel that practical benefits can be secured in the short term (whether or not they actually are)". En su intención de ofrecer pautas para el éxito empresarial a los cuadros directivos, existe una clara tendencia a definir qué es lo correcto y lo incorrecto en la tarea de la gestión organizacional. Por tanto, existe un componente comportamental muy importante, que trataremos de analizar más adelante en el presente escrito, ya que dicha vertiente de prescripción moral se traslada también a la sociedad en general.

Por tanto, cuando hablamos del discurso gerencial divulgado a través de la literatura del management, estaríamos hablando de un discurso moralizante que pretende guiar los comportamientos de los/as directivos/as hacia el éxito (Alonso y Fernández Rodríguez, 2013c). Las prescripciones se configuran en una dicotomía correcto-incorrecto en un sentido técnicoinstrumental, es decir, acciones acertadas o equivocadas entre las diferentes alternativas. Mientras que las decisiones correctas mejorarán la productividad y aumentarán la motivación del equipo de trabajo, las incorrectas provocarán lo contrario (Fernández Rodríguez, 2007). Dicha construcción dicotómica y prescriptiva nos otorga el escenario adecuado para reflexionar en torno a los discursos que se ponen en juego para configurar las subjetividades gerenciales no solamente de los gerentes, sino también de la población en general, que, al incorporar esta misma lógica, se amoldaría a los principios de la lógica mercantil neoliberal configurando las conocidas como "biografías del riesgo" (Beck y Beck-Gernsheim, 2003).

Volviendo a la posición del/la directivo/a como protagonista de los relatos aglutinados por la literatura managerial, resulta interesante reflexionar acerca de la imagen social que se crea sobre los mismos. Normalmente, los cargos directivos son percibidos como héroes que han de salvar a la empresa, otorgándoles gran poder como figuras de autoridad en la organización. Así 
pues, en lugar de centrarse en las complejidades que caracterizan a las organizaciones, las obras focalizan en el papel de los managers como ganadores o perdedores, buenos o malos, configurándoles como héroes carismáticos o villanos (Khurana, 2002). Esta imagen de los managers como personas de éxito a imitar se construyó para ser el modelo de comportamiento de la población, un modelo basado en valores como la creatividad, la innovación, la automejora, la autoexigencia y el emprendimiento (Alonso y Fernández Rodríguez, 2012, p. 2018).

Los individuos, al mirarse o verse reflejados diariamente en dicho modelo, empiezan a incorporar la misma lógica de comportamiento. Por esta razón, muchos de los valores que los caracterizan han sido incorporados en los discursos de la gente de a pie. Desde nuestra posición, consideramos que las confluencias entre la literatura popular del management y la literatura de autoayuda, son una muestra vital de que la segunda sirve de apoyo a la primera para difundir la lógica neoliberal y las premisas de la gestión de uno mismo entre la población general. Dicha difusión se realiza a través del lenguaje terapéutico, cuya lógica nos remite a una individualización de los problemas sociales, y a una autoresponsabilización por parte de los individuos de los condicionantes estructurales que les impiden realizar sus proyectos de vida.

En resumen, la literatura gerencial traslada los discursos o modas de gestión a los cargos de dirección empresarial, discursos que se atienen a los cambios sociales, de cualquier otro modo, perderían su vigencia rápidamente. Hoy en día, en su objetivo de informar a los cuadros directivos de las últimas innovaciones en materia de gestión de empresas y de dirección de personal, dicha literatura "se muestra como uno de los principales lugares de inscripción del espíritu del capitalismo" (Boltanski y Chiapello, 2002, p. 98). Al mismo tiempo, la propia lógica gerencial trasciende las fronteras del mundo de la gestión para pasar a formar parte del imaginario social. Dicha realidad nos permite deducir que la literatura gerencial reproduce los valores asociados a ese nuevo espíritu "influenciando la forma en que se organiza el trabajo dentro de las organizaciones" (Alonso y Fernández Rodríguez, 2013a, p. 42), pero no solamente esto, sino que condiciona también la configuración de las subjetividades contemporáneas más allá del mundo del trabajo, así como las relaciones sociales que se producen en las diferentes esferas sociales. Por esta razón, a continuación, trataremos de identificar las principales confluencias que se producen entre la literatura gerencial y la literatura de autoayuda, ya que consideramos que esta última se ha convertido en la herramienta de difusión principal de la lógica geren- 
cial hacia el público general. Es decir, la literatura de autoayuda sería un eco de la literatura gerencial, que amplía el público de recepción, pero que realmente sirve para difundir la misma lógica de gestión entre los individuos.

\section{Confluencias de la literatura gerencial con la literatura de autoayuda}

Resulta difícil marcar un punto de inicio para el desarrollo de la literatura de autoayuda, aunque una de las obras clave que suele citarse en este sentido es la de Cómo ganar amigos e influir en las personas de Dale $\mathrm{H}$. Carnegie (1936), libro que tal y como indica Papalini, "quizá fue el primero que expresara con nitidez las características del género" (2013, p. 167). Desde entonces, dicho género literario se ha convertido en una industria que genera millones de dólares, al igual que la industria de la literatura managerial (Micklethwait y Wooldridge, 1996). Incluso en un periodo de crisis económica mundial la revista Forbes señaló que este sector era casi el único que crecía, "la revista cifró en 11.000 millones de dólares la cantidad que los estadounidenses se gastaron en 2008 en libros de mejora personal, CDs, seminarios, coaching y programas para lidiar con el estrés" (Millet, 2015, p. 27). En consecuencia, se puede reconocer sin temor la vigencia social de este discurso psicologista y su éxito en una sociedad en la que la precariedad laboral, el predominio del individualismo y la incertidumbre son centrales (Laval y Dardot, 2018). Así pues, en este apartado partimos del reconocimiento de que la literatura de autoayuda es un síntoma clave de la pobreza emocional de los individuos, derivada de un contexto político y económico inestable y atravesado por la lógica de un capitalismo feroz. Cabe remarcar que la literatura de autoayuda no es un homogéneo constructo, sino que se conforma de diferentes subgéneros. Además, no se trata de un género invariable, sino que evoluciona y se desarrolla en función de los cambios históricos y las características de la sociedad (McGee, 2005). Sin embargo, en el presente artículo nos centraremos en los rasgos que en su acepción general comparten.

$\mathrm{Al}$ igual que ocurre con la literatura gerencial, "estos libros se caracterizan como un producto de la cultura masiva y, por lo tanto, destacan por la estereotipación de contenidos y su orientación hacia el mercado" (Canavire, 2014, p. 3). Tienen un gran carácter prescriptivo y moralizante, que llega al gran público y forma parte del imaginario social actual. Desde sus inicios va a existir una vertiente de la autoayuda dirigida al mundo empresarial, rasgo que nos indica que el mundo del trabajo va a ser uno de los 
espacios centrales donde el individuo va a necesitar recetas para su supervivencia. Para cumplir con dicho objetivo, la literatura de autoayuda tiene la capacidad de incorporar diferentes ideologías, convirtiéndolas en pautas y recetas a seguir (Papalini, 2013, p. 169), lo que permite que dichas pautas se presenten aparentemente sin ningún componente ideológico o de legitimación del capitalismo. Nada más lejos de la realidad, como trataremos de mostrar en el presente apartado.

Como se acaba de señalar, el carácter prescriptivo y el énfasis en la mercantilización de las capacidades de los individuos en la literatura de la autoayuda, establecen puentes de unión entre ésta y la literatura del management. Mientras que en la autoayuda el énfasis se pone en las capacidades del sujeto para superar sus propias limitaciones en un plano general (relaciones personales, amorosas, familiares, etc.); en la literatura del management, el individuo debe superar sus limitaciones en el mundo laboral. De este modo, las obras de autoayuda adquieren un cariz muy heterogéneo, ya que se tratan áreas que van desde la salud al trabajo, pasando por la autoesti$\mathrm{ma}$, problemas con los/as hijos/as, problemas sentimentales, de dinero, y un gran etcétera. A pesar de dicha heterogeneidad, la literatura de autoayuda comparte con las obras gerenciales la vulgarización de ideas expertas. Por esta razón, ambas establecen filosofías de vida, mediante la identificación de un problema y la aportación de posibles soluciones. Consecuentemente, al hablar de la literatura de autoayuda y compararla con la literatura gerencial, vemos que se produce un desplazamiento de la gestión de la empresa al plano individual. Se produce así una psicologización de la vida destinada a la consecución de la autogestión, que pasa inevitablemente por la gestión de las emociones.

Así, el desarrollo de la literatura de autoayuda se produce con la emergencia de lo que la socióloga Eva Illouz $(2007,2010)$ denomina "capitalismo emocional", concepto a partir del cual trata el papel de las emociones en la construcción del capitalismo. Su tesis central se refiere a la necesidad que tiene el capitalismo de instaurar una cultura emocional en la vida de los individuos que reproduzca las lógicas de intercambio del sistema económico. Desde nuestro punto de vista, la literatura de autoayuda es un instrumento clave en la conformación de dicha cultura emocional pro-capitalista y en su divulgación entre la gente de a pie, que se servirá del lenguaje terapéutico para alcanzar a la mayor parte de la población.

La autora señala la llegada del psicoanálisis a los EEUU, con la visita de Sigmund Freud a la Clark University (New York) en el año 1909, como el inicio de un nuevo estilo emocional que transformaría la concepción del yo 
de la cultura norteamericana (Illouz, 2010, p. 37), que después se trasladaría al resto del mundo. De este modo, nació un lenguaje terapéutico que tendría por objeto tratar las patologías de los individuos, relacionadas con malestares psíquicos que a su vez producía el propio sistema capitalista. Sin embargo, lo más interesante es comprobar cómo el mundo de la empresa se hizo eco de ese nuevo lenguaje para integrarlo en sus dinámicas, es decir, la psicología se introdujo en la empresa para garantizar la adhesión de los individuos a las nuevas dinámicas mercantiles y laborales (Illouz, 2007, p. 44). Y se extrapoló al resto de dimensiones sociales para garantizar la adhesión de la ciudadanía al neoliberalismo.

Una de las vías por las que se produce el establecimiento de dicho lenguaje terapéutico de la individualidad, es a través de la idea de autonomía que se divulga en la literatura de autoayuda. Así, aunque el concepto de autonomía sea una de las claves centrales del discurso de la autoayuda, pierde su significado primigenio para pasar a referirse a la obligación que cada cual tiene de cargar con el peso de su fracaso. Según señalan Ulrich Beck y Elisabeth Beck-Gernsheim (2003, p. 31), la noción de autonomía en la autoayuda nos habla de buscar soluciones biográficas a contradicciones sistémicas en el seno de una sociedad en la que la individualización y el aislamiento, por paradójico que parezca, se han convertido en experiencias colectivas de significación identitaria. Así pues, las formulaciones que encontramos en la literatura de autoayuda, y que ésta comparte con la literatura gerencial, responden a las necesidades de la modernidad líquida (Bauman, 2003) y al nuevo espíritu del capitalismo, tal y como se desprende de la siguiente cita:

Por ambas vías, la autonomía aparece como una mistificación más; la insistencia sobre el empoderamiento y la creatividad habilitan procesos de control y autocontrol en una lógica que demanda poco del Estado, las instituciones y las empresas. La astucia no radica en la incorporación de este término de vigoroso ascendiente sino en el modo en el que se ejercita la idea de autonomía, de evocaciones libertarias, legitima el trabajo a destajo, la precariedad del empleo, la flexibilidad del tiempo laboral que avanza sobre la vida privada, la multiplicación de las tareas que este involucra, la adaptación al cambio, la ausencia de marcos normativos y un compromiso total que no se circunscribe a la fuerza o a la capacidad de trabajo; se exigen cualidades subjetivas, tales como la imaginación para resolver los problemas y la constitución de una personalidad "amigable», a tono con los requerimientos de comunicación de las empresas (Papalini, 2013, pp. 176-177).

En una sociedad líquida y de capitalismo feroz, el individuo debe empoderarse si no quiere ser excluido del sistema. Si fracasa, el peso de dicho fracaso caerá sobre sus hombros y deberá levantarse solo, sin ayuda 
de otros individuos o instituciones. Desde esta perspectiva, las estructuras sociales no son condicionantes del éxito o fracaso de los individuos. Sin embargo, la realidad no se corresponde con esta idea, cuando entendemos que tanto el éxito como el fracaso están sujetos a diferentes variables en la vida de una persona. Como señala Richard Sennett (2000), los individuos entran a jugar dentro del juego capitalista, pero sin tener el control de las estructuras en las que se juega esta peculiar apuesta y sin estar habilitados para discutir las reglas. Así, se efectúa una operación cultural por la cual las soluciones a los problemas se encuentran dentro de los individuos, negando el papel del Estado y las empresas en la búsqueda de dicha solución. Las siguientes palabras de la socióloga Vanina Papalini (2006a, p. 42), reflejan de un modo acertado las cuestiones que estamos intentando plantear aquí: "No hay ninguna realidad externa a la psiquis que impida cumplir los propósitos que cada quien se forja. Todo parece ser una cuestión subjetiva, lo importante es cómo cada individuo se siente, se percibe a sí mismo y percibe su situación”.

Esta idea expuesta por Papalini nos remite directamente al valor del éxito, que también se encuentra muy presente en este tipo de literatura, quizás en un sentido más personal en la literatura de autoayuda y en un sentido más profesional en la literatura gerencial. Según Illouz, fue el psicólogo Abraham Maslow quien difundió esta noción capitalista de la autorrealización en la cultura norteamericana, que después tendrá su eco en el resto de sociedades. Dicha necesidad de autorrealización individual le llevó a proponer una hipótesis que se convertiría en base central del comportamiento humano en el capitalismo: "que el temor al éxito es lo que impide que una persona aspire a la grandeza y a la autorrealización" (Illouz, 2007, p. 103). Con esta operación se patologiza a todo aquél que no desee conseguir el éxito o que no lo haya conseguido tras intentarlo, teniendo en cuenta que, en un contexto neoliberal de desigualdades estructurales, son pocos los sujetos que lo van a conseguir. Sin embargo, también se le aportarán herramientas para conseguirlo, a través de la terapia (Viñas, 2012). Se patologiza el fracaso, convirtiéndolo en una especie de estigma social que va a condenar a todos aquellos que no estén dispuestos a autosacrificarse, a la invisibilidad social y el rechazo colectivo.

Consecuentemente, el ideal del éxito también varía cuando es utilizado en esta literatura, pasando de ser la consecución de algo que es social y colectivamente valorado, a una cuestión de autovaloración. En relación, Papalini recalca que el éxito en su sentido primigenio no sería un estado interior, sino que implica el reconocimiento de una realización y esto no 
deviene de uno mismo sino de una acción social. Sin embargo, la literatura de autoayuda incorpora un enfoque distinto: "la mirada de los demás, que sanciona el éxito o el fracaso, no cuenta; es uno mismo quien decide sobre la asignación de lauros, bajo un criterio puramente individual" (Papalini, 2006b, p. 338; 2010). De nuevo, somos testigos de una interiorización de los procesos sociales, así como de una individualización de cuestiones que con anterioridad eran construidas de forma conjunta o a través de la mirada de los/as otros/as. Esta es una idea que refleja de forma muy acertada los principios sobre los que se considera a alguien un "buen gerente".

Este proceso de individualización de los problemas sociales y otros temas, como por ejemplo el tratamiento individual de las consecuencias de la crisis económica en España (Alonso y Fernández Rodríguez, 2013a, 2013d), se desarrolla en paralelo al apogeo de la creatividad y la innovación social como fuente de desarrollo económico. Dichas premisas se articulan para conformar una nueva actitud en el individuo, que intentando huir de la precariedad, apostará por emprender su propio negocio. Así pues, desde una posición crítica, consideramos que dicha literatura muestra un total desinterés por realizar una explicación sistémica de los problemas sociales, situando la responsabilidad de la solución en manos individuales, desconectando los lazos que unen entre sí a los diferentes grupos sociales. Dicha realidad se ve reflejada también en la literatura del management, donde los contenidos se presentan de forma acrítica y sin prestar atención a los condicionantes sociales que los sustentan. Un ejemplo de dicha lógica aplicada a la literatura popular del management se puede ver en el bestseller titulado ¿Quién se ha llevado mi queso? (Johnson, 2000), donde se conciben los despidos como una "oportunidad" para pasar a una mejor situación (Papalini, 2013, p. 171).

Así, la literatura de autoayuda tiene un componente de desmovilización social, ya que desconecta a los individuos de la realidad en la que viven. Esto responde a su vez a una contribución acrítica al desarrollo del neocapitalismo. Y esto es algo de lo que también se nutre la literatura del management en general. En relación, el pensamiento positivo es una de las líneas de argumentación principales sobre las que se construye la literatura de autoayuda, y que, de igual modo, se extrapola a la empresa. Sin embargo, autoras como Barbara Ehrenreich (2012) nos advierten de las consecuencias sociales de este tipo de pensamiento centrándose en el caso de la sociedad norteamericana. Dicha autora advierte de que la última crisis financiera acontecida en los EEUU, de donde es oriunda, ha sido en parte producto de todas aquellas personas que han fundamentado sus decisiones 
en la ingenuidad del pensamiento positivo, por ejemplo, a la hora de pedir una hipoteca. Éste supone un claro ejemplo de cómo las ideas de la autoayuda y del management se difunden entre la población para fundamentar una actitud acrítica y entusiasta con el nuevo capitalismo, que permite su progresiva expansión sin demasiados límites.

De este modo, el componente individualizador que tiene la literatura de autoayuda la pone en confluencia con la literatura gerencial, hecho que lleva a que algunos autores consideren que este tipo de literatura no es más que una modalidad del management aplicada a la vida cotidiana (Hancock y Tyler, 2004). Y éste es un punto que nos resulta de enorme interés, ya que estamos argumentado la siguiente hipótesis: si la literatura del management se nutre de ciertas características de la literatura de autoayuda es porque al final comparten un mismo objetivo, esto es, situar la responsabilidad de los problemas sociales en un plano individual y configurar las subjetividades contemporáneas en función de la lógica neoliberal. Es decir, serían los individuos los encargados de paliar los efectos nocivos de la expansión capitalista, tratando de establecer proyectos de vida felices a golpe de autoayuda (Siurana, 2018).

Sin embargo, no debemos olvidar que para que la narrativa de autoayuda pueda gozar de éxito entre el público general, debe articularse sobre una narrativa del sufrimiento psíquico. Esto quiere decir que la autoayuda se nutre del malestar de los individuos, provocado por sus vivencias inestables y las contradicciones propias del capitalismo líquido de nuestros días. Illouz (2007, pp. 138-147; 2010, pp. 128-138) plantea el concepto de competencia emocional partiendo de la noción de habitus de Bourdieu (2012), dicha autora se refiere a un conjunto de prácticas y técnicas que permiten medir las emociones y jerarquizarlas, en vistas a alcanzar su control. Desde su perspectiva, la psicología ha redefinido el poder en términos emocionales, también dentro de la empresa. Esto quiere decir que la gerencia debe saber controlar sus emociones para gestionar la vida organizacional, "el control emocional señala una superioridad social" (Illouz, 2010, p. 135), que otorga a su vez una posición de control social a la élite directiva. Esta lógica de la gestión emocional que en principio se aplicaría al ámbito de las organizaciones, se extrapola de forma clara al grueso de la sociedad.

Así, dicho concepto está estrechamente relacionado con el de capital social, ya que, para generar dicho tipo de capital, es necesario que cada individuo se haga cargo de sus emociones y sepa gestionarlas desde una visión de mercado. Sin embargo, los modos en que se van a promover dichas conductas comportan una visión instrumental de la empresa y los individuos, tal y 
como plantea Gastón Souroujon (2009a, 2009b), quien estudia la ética de la autoayuda, subrayando su carácter instrumental. Dicho autor rastrea la concepción que del otro se realiza en este tipo de obras. Señala que se trata de obras enraizadas en una particular visión del "ideal de autenticidad" que naciera con Rousseau y se desarrollaría con el romanticismo (Souroujon, 2009a, p. 60). La autenticidad se refiere a la singularidad de cada uno, la idea de que somos seres únicos que deben encontrar su ser auténtico a través de la exploración e introspección (Taylor, 1994). Inevitablemente, esto conlleva un proceso de autorrealización que implica el reconocimiento de los/as otros/as. Es decir, existe una interdependencia entre el individuo y su búsqueda del yo mismo, con aquello que sucede en su entorno y las personas que se inscriben en él.

Sin embargo, la literatura de autoayuda se nutre de dicho ideal de autenticidad olvidando el componente de la interdependencia, de la "mutua necesidad" (Taylor, 1994, p. 73). Y al olvidarse de esta parte central del proceso de autorrealización, ignora el papel trascendental que tienen los demás en la conformación de nuestro propio ser, ya que dicha literatura terapéutica "insta a tratar a los demás como medios y como obstáculos, lo que no sólo implica la motivación de un comportamiento egoísta, limitando a veces con el solipsismo, sino que a su vez restringe la capacidad de autorrealización de los mismos individuos" (Souroujon, 2009a, p. 61). Concebir a los otros como meros instrumentos, construye un tipo de autorrealización que obliga a los individuos a renunciar a ciertos bienes que se hallan en el humus social y que solamente pueden conseguirse a través del ejercicio de los vínculos con los otros. De aquí se desprende un hecho importante y es que, el individuo perdería su responsabilidad para con los demás, la idea del otro entendido como un obstáculo para la consecución de los objetivos propios, se configura en el seno de la ética de la autoayuda como "una racionalización de los impulsos egoístas, la construcción de un argumento que legitima moralmente una conducta indiferente con relación al otro" (Souroujon, 2009a, p. 66). De este modo, se contribuye otra vez a la distorsión de las explicaciones colectivas de los problemas sociales, se impulsa una visión individualista e instrumental de las cuestiones sociales. Esta lógica se encuentra tanto en el ámbito gerencial, donde progresivamente se han ido desarticulando las redes de lucha sindical y asociacionismo, como en el escenario social, donde a pesar de las crecientes movilizaciones sociales de los últimos años (Dekker y Feenstra, 2015; Feenstra et al., 2017), nos encontramos aún con una mayoría de sujetos altamente individualizados. 
En este contexto "la noción de ejecutivo es algo más que la referencia a un lugar en la organización empresarial, se trata de una actitud ante la vida que privilegia el «actuar»" (Papalini, 2006a, p. 42). Ya sea en el ámbito de la empresa o en el social, para alcanzar una posición de éxito se debe actuar en consonancia con los valores pro-empresariales. En consecuencia, la literatura del management en sus confluencias con la literatura de autoayuda, permite a cualquier persona controlar sus emociones y ponerlas a jugar en el mercado permitiéndole desarrollar un comportamiento basado en la autorrealización, la búsqueda del éxito y el autocontrol desde una concepción instrumental. Todo aquél que no alcance el triunfo deberá estar dispuesto a aprender de los que sí lo han hecho, porque la responsabilidad de sobrevivir en el nuevo espíritu del capitalismo depende de la acción individual de cada cual. Por tanto, "los libros terapéuticos contemporáneos asumen un rasgo peculiar: fomentan la individualización, atribuyendo los distintos males -su origen y su desenlace- al ámbito personal” (Papalini, 2010, p. 150). Como vemos, las confluencias entre ambos tipos de literatura son innegables, ya que trasladan la gestión empresarial a la lógica de las vidas individuales. A continuación, trataremos de situar la razón de ser de ambas literaturas en un marco de sentido mayor referido a un proceso social concreto: la mercantilización de los individuos en el sistema neoliberal.

\section{La mercantilización de los individuos}

En el apartado anterior se han tratado las características de la literatura de la autoayuda y sus confluencias con la literatura popular del management. Al mismo tiempo, se ha comprobado que la divulgación del lenguaje terapéutico en la sociedad contemporánea responde al desarrollo del malestar que la posmodernidad y el capitalismo feroz causan en los individuos. En dicho contexto, valores como la autonomía, el éxito, la creatividad y el empoderamiento -ejes centrales de la imagen social de la clase gerencialpierden su poder de transformación social para convertirse en herramientas disciplinarias que el sujeto pone en funcionamiento para sobrevivir en un mercado cada vez más liberal. De este modo, ambos tipos de literatura contribuyen a la mercantilización de las capacidades de los individuos, esto es, la incorporación moral de los valores economicistas por parte del individuo en su quehacer diario. Una operación que busca la incorporación de la autogestión por parte de los individuos, que empiezan a concebirse a sí mismos como empresas. A continuación, trataremos dicho proceso focalizando en 
tres discursos que confluyen para fundamentar culturalmente la mercantilización de la vida privada y las capacidades de las personas. Nos referimos a la formación del sujeto neoliberal a través de la educación desligada de los valores democráticos, la precariedad como herramienta disciplinaria y el discurso de la innovación social.

La difusión de los discursos gerenciales se encuentra irremediablemente ligada a la formación del sujeto neoliberal, ya que, sin la existencia de dicho sujeto, los principios de gestión que son divulgados a través de dicha literatura carecerían de un público objetivo tan amplio y asentado, y, por tanto, no podrían arraigar en el imaginario social tal y como lo han hecho. El éxito de la literatura del management así como de la literatura de autoayuda responde a una realidad, y es que la lógica de la gestión empresarial ha ocupado todos los espacios sociales. Esto quiere decir que ya no son sólo los managers quienes conciben el mundo en términos de rentabilidad, sino que los individuos de a pie también han incorporado el discurso de la empresa en su lógica vital. Dicha operación se ha producido a través de un entramado cultural, político y económico complejo que contiene la confluencia de diferentes discursos: educación, precariedad e innovación. Para comprender la complejidad de dicha afirmación, empezaremos tratando uno de los factores centrales en la construcción educativa del nuevo sujeto neoliberal: los sistemas educativos actuales.

La expansión del modelo económico de la globalización ha generado grandes injusticias sociales y ha empeorado la situación de numerosos países y grupos humanos. A pesar de estas desigualdades, parece que dicho proceso goza de una gran legitimidad social. Una de las razones es que la lógica de mercado se ha convertido en la lógica de las relaciones sociales, haciendo que la cultura de empresa sea inculcada a la ciudadanía desde la escuela hasta los medios de comunicación. Según el autor Enrique Díez Gutiérrez (2007), el aparato neoliberal ha conseguido desideologizar sus políticas hasta el punto de que sus acciones no se ponen en entredicho, y en este proceso las instituciones educativas juegan un papel vital. Atendiendo a este razonamiento, consideramos de vital importancia abordar el papel de las instituciones educativas en este proceso, ya que, de algún modo, también este ámbito refleja la lógica gerencial divulgada en la literatura gerencial y de la autoayuda.

Y es que, resulta obvio que la globalización ha traído cambios radicales en las formas de relacionarnos, necesitando que integremos valores concretos para legitimar estas nuevas relaciones basadas en la eficacia y el rendimiento, sin tener que pararnos a reflexionar sobre sus efectos. Esto quiere 
decir que, tal y como señalaron Horkheimer y Adorno (1998), quienes ya en 1944 llamaron la atención sobre la razón instrumental como gobernadora de la vida social y personal, en el escenario actual dicha lógica hace que rijamos nuestras relaciones en base a la premisa de maximización de beneficios y el universo de competitividad generalizada. De este modo, vemos que el pensamiento único derivado del auge del sistema neoliberal en nuestra sociedad se sostiene gracias al entramado ideológico educativo y de socialización que nos rodea.

Las instituciones educativas juegan un papel central como legitimadoras del sistema neoliberal y formadoras de los individuos en los valores de mercado. A colación traemos el trabajo del filósofo Axel Honneth (2013), quien examina la relación interna entre educación y democracia, en vistas a señalar la desconexión que se ha producido entre ambas en las últimas décadas. Desde su posición, dicha desconexión responde a los nuevos intereses de los Estados, que ya no tienen como prioridad la educación cívica de sus ciudadanos/as, sino la expansión de la lógica neoliberal y la financiarización de la sociedad (Alonso y Fernández Rodríguez, 2012). Por tanto, si tenemos en cuenta que no es posible que existan estados democráticos y justos si no hay educación democrática, entenderemos porqué actualmente los valores inculcados en la escuela tienen más que ver con el mercado que con la democracia.

Según Honneth, en los sistemas educativos de las sociedades occidentales se apela al mandato de neutralidad del Estado heredero del pensamiento liberal para "que incluso la idea de la educación democrática pierda su naturalidad normativa" (Honneth, 2013, p. 384). Es decir, se promueve el papel neutral del Estado a la hora de diseñar los planes educativos, como una respuesta de justicia frente al creciente número de culturas que pueden convivir en un mismo Estado. Por tanto, el desplazamiento teórico que sufre el concepto de neutralidad "es la consecuencia no intencionada del propósito, bienintencionado en su conjunto, de hacer justicia al creciente pluralismo de culturas étnicas y religiosas en nuestras sociedades poniendo el acento en la neutralidad estricta de la educación organizada por el Estado" (Honneth, 2013, p. 383). Sin embargo, dicha bienintencionada cuestión ha derivado en la conformación de una escuela "neutral" impregnada de los valores economicistas, que sirven a la legitimación del sistema económico globalizado. La idea de neutralidad pasa de ser entendida aquí como una posible vía para la justicia en referencia a diferentes grupos étnicos, a una neutralidad economicista y racionalista que permite difundir la lógica neoliberal entre el alumnado. 
Así pues, bajo la apariencia de neutralidad, dichas enseñanzas están inculcando en la población una propensión a aceptar las injusticias generadas por el sistema neoliberal. Tal y como habíamos visto con la literatura de autoayuda, dicha realidad se legitima cuando los individuos dejan de atender a las estructuras sociales, solamente prestando atención a lo individual. De este modo, Honneth $(2013$, p. 393) señala que en el actual sistema educativo invadido de los intereses neoliberales, el/la alumno/a es tratado "como un sujeto aislado que debe arrojar un rendimiento", y que dicha realidad no contribuye a formar a la ciudadanía en los valores democráticos necesarios para una convivencia real en los tiempos actuales. Dicha operación es una muestra de cómo la razón instrumental impregna los ámbitos sociales y cómo el modelo de homo oeconomicus se ha convertido en la lógica de acción central de nuestro día a día (Díez Gutiérrez, 2014, pp. 40-41). A su vez, nos muestra cómo el discurso de la autogestión que encontramos en la literatura gerencial y en la literatura de autoayuda no es algo aislado, sino que se ha convertido en la columna vertebral de los discursos sociales de nuestro tiempo, que se encuentran también en el ámbito educativo.

Se trata de desarticular el entramado democrático y la formación de los/ as ciudadanos/as en dichos valores, para convertirlos en sujetos preparados para participar en el mercado neoliberal. Se trata de que cada individuo tenga las herramientas necesarias para incorporar el ethos empresarial maximizador de beneficios como parte de su propia moral. Uno de los ejemplos de este proceso lo encontramos en el gran valor que se otorga hoy en día al emprendimiento empresarial y a explotar el capital que supuestamente todos los individuos tienen en su interior (Binkley, 2011; Gill, 2019; Riesman, 1998; Scharff, 2015a). Dicho énfasis en el yo emprendedor nos remite de nuevo a una individualización de los problemas sociales y a una banalización de las desigualdades e injusticias que genera la globalización y un modelo de economía instrumental. La legitimación de dichas injusticias pasa por culpabilizar a la víctima del sistema, lo que quiere decir que problemas sociales como el desempleo son puestos en manos de los propios desempleados, culpabilizándoles de su incapacidad de emprender y aprovechar las oportunidades que supuestamente les brinda el mercado.

A través de la ruptura entre pedagogía y filosofía política y la inserción de valores propios del homo oeconomicus en los sistemas educativos, crece la instrumentalización del individuo. Esto junto a la expansión del nuevo espíritu del capitalismo promueve la "explotación de uno mismo" (Han, 2012) como el proyecto vital por excelencia. Dicha realidad se encuentra estrechamente ligada a la precariedad a la que están sujetos los individuos, 
hecho que les sitúa en una situación social de gran fragilidad. El modelo de educación que acabamos de señalar, contribuye a que dicha precariedad no sea percibida como una razón para la lucha y la transformación social, sino para incorporar con más ahínco los valores economicistas en su práctica diaria. En cierta medida la literatura de autoayuda contribuirá a reforzar como tipo ideal "una suerte de individuo que procede a autorregular su comportamiento y emocionalidad en pro del bienestar psíquico y, en última instancia, en aras de su felicidad" (Ampudia de Haro, 2006, p. 70). Una felicidad que se ha convertido en toda una industria basada en argumentos pseudocientíficos para llegar al control total de nuestras vidas (Cabanas y Illouz, 2019; Papalini, 2016).

Por ejemplo, se insta a los individuos a pensar en términos de rentabilidad, incluso en lo que se refiere a conformar su currículum personal. Se invierten años de esfuerzo y dinero en mejorar la formación con la esperanza de que de este modo se conseguirá un empleo y con él, cierta estabilidad. Sin embargo, al encontrarse totalmente insertos en la lógica del capital, los individuos no parecen percatarse de que "el mecanismo de control se establece sobre la base de pedir más, de no haber nunca un límite a lo exigible: nunca se tendrá suficiente grado de formación, suficiente compromiso con la organización, suficiente rendimiento" (Alonso y Fernández Rodríguez, 2013b, pp. 131-132). Esto refuerza el afán de competitividad, además del hecho de que la gestión del riesgo que antes corría a cargo del Estado y más tarde de las empresas, ahora corre a cargo del individuo.

Esta precariedad se enmarca en la sociedad del riesgo donde la flexibilidad y la inseguridad se convierten en centro del sentido social compartido. Se trata de un contexto donde la precariedad no solamente va a afectar a las relaciones de trabajo, sino que va a transformar la noción de ciudadanía, de individuo, y las dinámicas empresariales y estatales. De este modo, a través del nuevo espíritu del capitalismo estudiado por Luc Boltanski y Éve Chiapello, se entiende que esta nueva etapa requiere de un compromiso con el sistema capitalista elaborado autónomamente por parte de los sujetos. Es decir, ahora la sujeción no se produce tanto por la represión como por la vivencia autónoma de los individuos. Se configuran nuevas subjetividades y relaciones de los sujetos con las instituciones sociales y económicas basadas en la autoexplotación. Los sociólogos Luis Enrique Alonso y Carlos Jesús Fernández Rodríguez (2013b, pp. 130-132) consideran que dicha precariedad actúa como un fenómeno disciplinario, una técnica biopolítica, en términos foucaultianos, por la cual los/as trabajadores/as de la época posfordista se encuentran abandonados a las exigencias del mercado 
capitalista. En cierto modo, la lógica argumental del precariado promueve la autoexplotación poniendo en el propio sujeto el miedo y la incertidumbre (Berardi, 2003).

Por tanto, los nuevos recorridos vitales que se emprenden en la etapa neoliberal comportan la subjetivación individual de la flexibilidad y la eventualidad, lógicas que afectan a la alimentación, la planificación del tiempo, las posibilidades de establecer una familia, la residencia y, en definitiva, la construcción de una realidad donde la gestión de las emociones se vuelve central. Así, la progresiva desprotección de los individuos por parte de instituciones y la obligación de tomar decisiones forzadas que tienen pocas posibilidades de éxito, actúan aquí como factores de riesgo. De esta manera, se idealiza la predisposición al cambio del individuo, pero no se tienen en cuenta las condiciones materiales sobre las que este cambio se va a llevar a cabo, ni los costes emocionales y sociales que el fracaso tiene para estas personas. La precariedad, por tanto, forma parte de las realidades sobre las que se sustenta la mercantilización de los individuos (Muñoz-Rodríguez y Santos-Ortega, 2017).

Al mismo tiempo, el discurso sobre la innovación social se conforma como una de las bases del capitalismo líquido y del discurso del management (Alonso y Fernández Rodríguez, 2011), a la vez que está relacionado con la precariedad y la educación economizada. La innovación social surge como una búsqueda de la mejora o la reforma social, mientras que con el tiempo evoluciona al equivalente de fenómenos empresariales como Google o Facebook. Al mismo tiempo, se asocia con regiones o países del mundo que han conseguido insertarse de forma exitosa en la Sociedad del Conocimiento. En este sentido, Alonso y Fernández (2011, p. 1135) identifican las bases de dichos discursos en tres ejes centrales: creatividad, adaptabilidad y el protagonismo de los Estados para impulsar la innovación. Así, el concepto de innovación social sufre un desplazamiento semántico, sirviendo de base al concepto de competitividad. Por esto en muchos de los trabajos sobre innovación social existe "una visión de la innovación totalmente despolitizada, pragmática y economicista, desconcertantemente alejada de cualquier idea de conflicto social, divergencia de intereses o actores sociales con diferentes estrategias y prácticas" (Alonso y Fernández Rodríguez, 2011, p. 1142).

Bajo la aparente innovación del discurso de la gestión, no se hallan deseos de una mejora social, sino la consecución de fines instrumentales. No hay que olvidar que la promoción de la creatividad se dirige a generar empresas más competitivas en un contexto globalizado, y sujetos más vulnerables 
en un contexto precario. Como la burocracia no tiene lugar en esta nueva empresa, la horizontalidad y la cooperación son valores que marcan el ritmo del capitalismo postfordista, los individuos deben estar preparados para la incertidumbre. Atendiendo a dicha realidad, la educación que reciban los/as ciudadanos/as se convierte en un factor esencial, ya que será aquello que los convierta en un buen precariado (Standing, 2011) sujeto a los dictámenes de la innovación social.

En resumen, consideramos que tanto la literatura gerencial como la literatura de autoayuda contribuyen a difundir la lógica neoliberal y de a autogestión entre los individuos. Dicha lógica se centra principalmente en la confluencia de tres discursos: la formación del sujeto neoliberal a través de la educación desligada de los valores democráticos, la precariedad como herramienta disciplinaria y el discurso de la innovación social. A través de este tridente discursivo, se contribuye a llevar hacia adelante el proceso de la mercantilización de las capacidades de los individuos. Para terminar, cabe señalar que el carácter acrítico de estos discursos y del lenguaje terapéutico que caracteriza tanto a la literatura gerencial como a la de la autoayuda, crea una nueva clase de subjetividades determinadas por los valores de la autoexplotación, la automejora y la autoexigencia.

\section{Conclusión}

A lo largo de este trabajo hemos podido comprobar que la literatura gerencial y la literatura de autoayuda tienen muchos puntos de confluencia. Una de las características intrínsecas de ambas es la capacidad de distorsionar o reformular conceptos como el de autenticidad y autonomía, autorrealización y éxito, para ajustarlos a las necesidades del nuevo espíritu del capitalismo. A su vez, dichas reformulaciones se producen como causa y consecuencia de la inmersión de las emociones en el mundo de la empresa, la comercialización de las emociones en el capitalismo emocional. Pero también del traspaso de la lógica gerencial al mundo de las relaciones sociales.

Este capital emocional permite a los individuos acceder a la empresa o, mejor dicho, gestionarse a sí mismos como una empresa, a través del ejercicio de la competencia emotiva que permite generar capital social en la nueva sociedad red. De este modo, una de las vías más efectivas para permitir dicha realidad es fomentar el control emocional de los individuos, es decir, jerarquizar las emociones según las preferencias o necesidades del sistema capitalista. Las recetas para potenciar según qué capacidades vendrán de la 
mano de la literatura de autoayuda en una acepción general y de la literatura del management en una vertiente dirigida en especial a la empresa.

En este contexto el management se convierte en un dispositivo que articula las prácticas de subjetivación contemporáneas que propone a los individuos modos de acción sobre sí mismos (Zangaro, 2011). En términos foucaultianos, el discurso del management, así como su divulgación a través de ambas literaturas, funcionaría como una tecnología del poder. Según esta perspectiva, la literatura managerial ejercería no solamente de aglutinadora de los discursos que hemos visto, sino que influiría en la conformación de la subjetividad de los individuos y su predisposición al emprendimiento y una suerte de autoexplotación. Así, las principales prácticas discursivas y reconceptualizaciones sobre las que se sostiene la lógica neoliberal de nuestro tiempo actúan como métodos disciplinarios para la mercantilización de las estructuras estatales y las vidas de los individuos. Por tanto, a través de la literatura del management y la literatura de autoayuda no solamente se están divulgando dichos discursos de forma entrelazada, sino que se está contribuyendo a la difusión del modelo neoliberal empresarial como "categoría de modelo de subjetivación” (Díez Gutiérrez, 2014, p.46).

Dicho discurso se difunde a través de las instituciones educativas que preparan a los sujetos para explotar sus capacidades en el escenario de capitalismo feroz; y encuentran su máxima expresión en los textos manageriales que actúan como mecanismo disciplinario dentro de las organizaciones, y los textos de autoayuda, que actúan como mecanismo disciplinario en las otras esferas sociales. Así pues, se hace necesario introducir en la institución escolar contenidos sociopolíticos que vayan quebrando la idea de falsa neutralidad del sistema educativo. Esto a su vez, ayudaría a que el individuo fuese capaz de extrapolar sus experiencias precarias al grueso social, identificando las estructuras colectivas que propician ciertas desigualdades. Llegados a este punto podemos señalar que la validez del discurso del management entre la población general y no solamente entre el público referido a la empresa, se basa en la proliferación de los principios del homo oeconomicus entre la ciudadanía. La autoexplotación y la mercantilización de las capacidades de cada individuo son un claro caldo de cultivo para que el éxito de este tipo de literatura siga extendiéndose más allá de los límites de la empresa. 


\section{Bibliografía}

Abrahamson, Eric. 1991. Managerial Fads and Fashions: The Diffusion and Rejection of Innovations. Academy of Management Review, vol. 16, n. 3, pp. 586-612. https://doi.org/10.5465/amr.1991.4279484

Adler, Paul, Forbes, L., y Hugh Willmott. 2007. Critical Management Studies. The Academy of Management Annals, vol. 1, n. 1, pp. 119-179. https://doi.org/10.5465/078559808

Alonso, Luis Enrique, y Carlos Jesús Fernández Rodríguez (2006). El imaginario managerial: el discurso de la fluidez en la sociedad económica. Politica y Sociedad, vol. 43, n. 2, pp. 127-151.

Alonso, Luis Enrique, y Carlos Jesús Fernández Rodríguez (2011). La innovación social y el nuevo discurso del management: limitaciones y alternativas. Arbor. Ciencia, Pensamiento y Cultura, vol. 187, n. 752, pp. 1133-1145. https://doi.org/10.3989/arbor.2011.752n6009

Alonso, Luis Enrique, y Carlos Jesús Fernández Rodríguez (2012). La financiarización de las relaciones salariales. Una perspectiva internacional. Madrid: Los libros de la Catarata.

Alonso, Luis Enrique, y Carlos Jesús Fernández Rodríguez (2013a). Debemos aplacar a los mercados: el espacio del sacrificio en la crisis financiera actual. Vínculos de Historia, n. 2, pp. 97-119.

Alonso, Luis Enrique, y Carlos Jesús Fernández Rodríguez (2013b). Los discursos del management. Una perspectiva crítica. Lan Harremanak, vol. 28, n. 1, pp. 42-69.

Alonso, Luis Enrique, y Carlos Jesús Fernández Rodríguez (2013c). Los discursos del presente. Un análisis de los imaginarios sociales contemporáneos. Madrid: Siglo XXI.

Alonso, Luis Enrique, y Carlos Jesús Fernández Rodríguez (2013d). Sacrificios para aplacar a los mercados: violencia y dominación en la crisis financiera. Documentación social, n. 169, pp. 65-84.

Alonso, Luis Enrique, y Carlos Jesús Fernández Rodríguez (2018). Poder y sacrificio. Los nuevos discursos de la empresa. Madrid: Siglo XXI.

Alvesson, Mats, y Huge Willmott (1992). Critical Management Studies. London: Sage.

Ampudia de Haro, Fernando (2006). Administrar el yo: literatura de autoayuda y gestión del comportamiento y los afectos. Reis. Revista Española de Investigaciones Sociológicas, n. 113, pp. 49-72. 
Bauman, Zigmunt (2003). Modernidad líquida. Buenos Aires: Fondo de Cultura Económica.

Beck, Ullrich, y Elisabeth Beck-Gernshei (2003). La individualización: el individualismo institucionalizado y sus consecuencias sociales y políticas. Barcelona: Paidós.

Berardi, Franco (2003). La fábrica de la infelicidad. Madrid: Traficantes de sueños.

Binkley, Samuel (2011). Psychological Life as Enterprise: Social Practice and the Government of Neo-liberal Interiority. History of the Human Sciences, vol. 24, n. 3, pp. 83-102. https://doi.org/10.1177/0952695111412877

Boltanski, Luc, y Ėve Chiapello (2002). El nuevo espíritu del capitalismo. Madrid: Akal.

Bourdieu, Pierre (2012). Bosquejo de una teoría de la práctica. Buenos Aires: Prometeo.

Bröckling, Ulrich (2015). El Self emprendedor. Sociología de una forma de subjetivación. Santiago de Chile: Editorial Universidad Alberto Hurtado.

Cabanas, Edgar, y Eva Illouz (2019). Happycracia. Cómo la ciencia y la industria de la felicidad controlan nuestras vidas. Barcelona: Paidós.

Canavire, Vanina B. (2014). Hacia un paradigma de lectura de géneros masivos: el caso de la literatura «de autoayuda». Álabe. Revista de la Red de Universidades Lectoras, n. 9, pp. 1-18. https://doi.org/10.15645/Alabe.2014.9.4

Carnegie, Dale H. 1936. Cómo ganar amigos e influir en las personas. New York: Pocket Books.

Collins, David (2000). Management Fads and Buzzwords. London: Routledge.

Dekker, Paul, y Ramón A. Feenstra. 2015. Activism and Civil Society: Broadening Participation and Deepening Democracy. Recerca. Revista de pensament $i$ anàlisi, n. 17, pp. 7-14. https://doi.org/10.6035/Recerca.2015.17.1

Díez Gutiérrez, Enrique Javier (2007). La globalización neoliberal y sus repercusiones en la educación. Barcelona: El Roure.

Díez Gutiérrez, Enrique Javier (2014). La construcción educativa del nuevo sujeto neoliberal. El Viejo Topo, n. 320, pp. 39-47.

Ehrenreich, Barbara (2012). Sonríe o muere. La trampa del pensamiento positivo. Madrid: Editorial Turner.

Feenstra, Ramón A., Tormey, Simon, Casero-Ripollés, Andreu, y John Keane (2017). Refiguring Democracy: The Spanish Political Laboratory. London and New York: Routledge. https://doi.org/10.4324/9781315160733 
Fernández Rodríguez, Carlos Jesús (2007). El discurso del management: tiempo y narración. Madrid: Centro de Investigaciones Sociológicas.

Foucault, Michel (2007). Nacimiento de la biopolítica. Buenos Aires: Fondo de Cultura Económica.

Gantman, Ernesto (2017). En torno al potencial transformador de los CMS (Critical Management Studies). Recerca. Revista de pensament i anàlisi, n. 20, pp. 15-33. https://doi.org/10.6035/Recerca.2017.20.2

Gill, Rosalind (2019). Cuando la propia vida es el campo laboral. Recerca. Revista de Pensament $i$ Anàlisi, n. 24, vol. 1, pp. 14-36. https://doi.org/10.6035/Recerca.2019.24.1.2

González Gil, Isabel (2018). Retórica de los libros de autoayuda. $452^{\circ} \mathrm{F}$. Revista de Teoría de la literatura y Literatura comparada, n. 19. Gowler, Dan, y Karen Legge (1991). Images of Employees in Company Reports - Do Company Chairmen View their Most Valuable Asset as Valuable? Personnel Review, vol. 20, n. 3, pp. 9-18. https://doi.org/10.1108/ EUM0000000000793

Han, Byung-Chul. 2012. La sociedad del cansancio. Barcelona: Herder.

Hancock, Phillip, y Melissa Tyler. 2004. «MOT your life»: Critical Management Studies and the Management of Everyday Life. Human Relations, vol. 57, n. 5, pp. 619-645. https://doi.org/10.1177/0018726704044312

Honneth, Axel (2013). La educación y el espacio público democrático. Un capítulo descuidado en la Filosofía Política. ISEGORÍA. Revista de Filosofía Moral y Política, n. 49, pp. 377-395. https://doi.org/10.3989/ isegoria.2013.049.01

Horkheimer, Max, y Theodor W. Adorno (1998). Dialéctica de la Ilustración. Fragmentos filosóficos. Madrid: Trotta.

Huczynski, Andrzej (1993). Explaining the Succession of Management Fads. International Journal of Human Resource Management, vol. 4, n. 2, pp. 444-463. https://doi.org/10.1080/09585199300000023

Huczynski, Andrzej (2006). Management Gurus. New York: Routledge. Illouz, Eva (2007). Intimidades congeladas. Buenos Aites: Katz Editores. https://doi.org/10.2307/j.ctvndv74r

Illouz, Eva (2010). La salvación del alma moderna. Madrid: Katz Editores. https://doi.org/10.2307/j.ctvm7bf7f

Jackson, Brad (2002). Management Gurus: What Can We Really Learn from Them? Mt Eliza Business Review, vol. 4, n. 2, pp. 67-72.

Johnson, Spencer (2000). ¿Quién se ha llevado mi queso? Barcelona: Urano. 
Khurana, Rakesh (2002). Searching for a Corporate Savior: The Irrational Quest for Charismatic CEOs. New Jersey: Princeton University Press. https://doi.org/10.1515/9781400841097

Laval, Christian, y Pierre Dardot (2013). La nueva razón del mundo. Ensayo sobre la sociedad neoliberal. Barcelona: Gedisa.

Laval, Christian, y Pierre Dardot (2018). El ser neoliberal. Barcelona: Gedisa. López-Ruiz, Osvaldo (2007). "Ethos empresarial: el "capital humano" como valor social”. Estudios Sociológicos, n. XXV, 399-425.

McGee, Micki (2005). Self Help, Inc. Oxford: Oxford University Press. https://doi.org/10.1093/acprof:oso/9780195171242.001.0001

McGuigan, Jim (2014). The Neoliberal Self. Culture Unbound, vol. 6, pp. 223-240.

https://doi.org/10.3384/cu.2000.1525.146223

Micklethwait, John, y Adrian Wooldridge (1996). The Witch Doctors. London: Heinemann.

Millet, Eva (2015). Autoayuda SA. Magazine Digital. Disponible en: http:// www.magazinedigital.com/historias/reportajes/autoayuda-sa

Muñoz-Rodríguez, David, y Antonio Santos-Ortega (2017). «Las cárceles del capital humano: trabajo y vidas precarias en la juventud universitaria.» Recerca. Revista de pensament $i$ anàlisi, n. 20, pp. 59-78.

https://doi.org/10.6035/Recerca.2017.20.4

Papalini, Vanina (2006a). La subjetividad disciplinada: de la contracultura a la autoayuda. En Papalini, Vanina (ed.). La comunicación como riesgo: cuerpo y subjetividad. La Plata: Al Margen, pp. 21-44.

Papalini, Vanina (2006b). Literatura de autoayuda: una subjetividad del SíMismo enajenado. La trama de la comunicación, n. 11, 331-342.

Papalini, Vanina (2010). Libros de autoayuda: biblioterapia para la felicidad. Athenea Digital. Revista de Pensamiento e Investigacion Social, vol. 169, n. 19, pp. 147-169. https://doi.org/10.5565/rev/athenea.722 https://doi.org/10.5565/rev/athenead/v0n19.722

Papalini, Vanina (2013). Recetas para sobrevivir a las exigencias del neocapitalismo. Nueva Sociedad, vol. 245, pp. 163-177.

Papalini, Vanina (2016). Garantías de felicidad: estudio sobre los libros de autoayuda. Buenos Aires: Adriana Hidalgo Editora.

Riesman, David (1998). On Higher Education: The Academic Enterprise in an Era of Rising Student Consumerism. Chicago: University of Chicago Press.

Rimke, Heidi Marie (2010). Governing Citizens Through Self-Help Literature. Cultural Studies, vol. 14, n. 1, pp. 61-78. https://doi. org/10.1080/095023800334986 
Scharff, Christina (2015a). Life as an enterprise: Ten ways through which neoliberalism is experienced on an emotional level. The London School Of Economics and Political Science [en línea]. Disponible en: http:// blogs.lse.ac.uk/politicsandpolicy/the-psychic-life-of-neoliberalism/

Scharff, Christina (2015b). The Psychic Life of Neoliberalism: Mapping the Contours of Entrepreneurial Subjectivity. Theory, Culture y Society, vol. 33, n. 6, pp. 107-122. https://doi.org/10.1177/0263276415590164

Sennett, Richard (2000). La corrosión del carácter. Barcelona: Anagrama. Siurana, Juan Carlos (2018). Felicidad a golpe de autoayuda. Madrid: Plaza y Valdés.

Souroujon, Gastón (2009a). «El infierno son los demás». La concepción del otro en la ética de la autoayuda. Athenea Digital. Revista de Pensamiento e Investigacion Social, vol. 75, n. 16, pp. 59-75.

Souroujon, Gastón (2009b). Los libros de autoayuda, ¿el último vástago del Romanticismo? Ciencia, Docencia y Tecnología, n. 38, pp. 87-114.

Standing, Guy (2011). The Precariat. The New Dangerous Class. New York: Bloomsbury Academic.

Taylor, Charles (1994). La ética de la autenticidad. Barcelona: Paidós.

Viñas, David (2012). Erótica de la autoyuda. Estrategias narrativas para promesas terapéuticas. Barcelona: Ariel.

Weick, Karl E. (1995). Sensemaking in Organizations. Thousan Oaks: Sage. Zangaro, Marisa B. (2011). Subjetividad y trabajo. Una lectura foucaultiana del management. Buenos Aires: Herramienta. 